\title{
CITIZENS' PERCEPTIONS OF POLITICAL PROCESSES A critical evaluation of preference consistency and survey items
}

\author{
LAPERCEPCIÓN DEL PROCESO POLITICO POR PARTE DE LOS CIUDADANOS \\ Una evaluación crítica de la consistencia de las preferencias y las preguntas de encuesta
}

\author{
ÅsA BENGTsson asa.bengtsson@abo.fi \\ Åbo Akademi University. Finland.
}

\begin{abstract}
The current state of research does not tell us much about citizens' expectations of political decision making. Most surveys allow respondents to evaluate how the current system is working, but do not inquire about alternative political decision-making procedures. The lack of established survey items can be explained by the fact that radical changes in decision-making procedures have been hard to envisage, but also by a general scepticism regarding people's ability to form opinions on these matters. Political processes are, without doubt, complex matters that do not lend themselves very well to simplistic survey questions. Moreover, previous research has convincingly shown that most people in general have difficulties forming single, coherent and stable attitudes even towards far more straightforward political issues. In order to determine if trying to grasp attitudes towards political decision-making in future empirical studies can be considered a fruitful endeavour, this study sets out to critically assess the extent to which people express coherent preferences on these matters, and if preferences are in line with expectations in previous, rather scattered research. The study is based on the Finnish National Election Study 2011; a study which, contrary to most other election studies, includes a rich variety of survey items on the topic, and utilises a combination of strategies in order to explore patterns in the opinions held by citizens.
\end{abstract}

\section{KEYWORDS}

Citizen preferences; Direct democracy; Political decision making; Representative democracy; Stealth democracy.

\section{RESUMEN}

El estado actual de las investigaciones no nos dice mucho sobre las expectativas de los ciudadanos con respecto a la toma de decisiones políticas. La mayoría de las encuestas permiten que quienes las responden evalúen cómo funciona el sistema actual, pero no preguntan por procedimientos alternativos de decisión política. La falta de preguntas de encuesta contrastadas se puede explicar tanto por el hecho de que los cambios en los procedimientos de toma de decisiones han resultado difíciles de prever, como por el escepticismo general con respecto a la capacidad de las personas para formarse una opinión sobre estos asuntos. Los procesos políticos son, sin duda, asuntos complejos que no se prestan bien a preguntas simplistas de encuesta. Además, los estudios previos han demostrado convincentemente que la mayoría de la gente tiene dificultades en general para adoptar una actitud única, estable y coherente que tenga que ver con asuntos políticos incluso mucho más directos. Para determinar si el hecho de intentar captar las actitudes hacia la toma de decisiones políticas en futuros estudios empíricos es una empresa fructífera, este estudio pretende valorar críticamente hasta qué punto la gente expresa preferencias coherentes sobre estos asuntos, y si esas preferencias están en consonancia con lo que se esperaba en las dispersas investigaciones previas. Este estudio se basa en la Encuesta Electoral Finlandesa de 2011, un estudio que, a diferencia de la mayoría de los estudios electorales, incluye una rica variedad de preguntas de encuestas sobre este tema y utiliza una combinación de estrategias para buscar algún patrón en la opinión de los ciudadanos.

\section{Palabras Clave}

Democracia directa; Democracia furtiva; Democracia representativa; Preferencias ciudadanas; Toma de decisiones políticas. 


\section{INTRODUCTION}

In recent decades, citizens have become more critical of the actors and institutions that form the basis of the representative democratic process, while turnout in elections as well as party membership have been in decline; a development described as a challenge to representative democracy. The most commonly suggested action in order to overcome this challenge has been to bring people back into politics with the use of more participatory forms of democracy. However, it appears likely that the success of such an endeavour is dependent on the support of citizens; support that is yet to be confirmed by systematic empirical research. If citizens do not consider this a desirable development, it is highly questionable if advances towards a more diverse set of opportunities for engaging in political issues can offer a cure to the malaise that has afflicted representative democracies around the world.

Citizens' preferences concerning political decision making is in fact a highly neglected issue in the field of opinion research, resulting in a lack of systematic and balanced information. To a large extent, this insufficient knowledge is due to a lack of well-functioning and established survey items on the topic. Standard investigations of public opinion tend to be output or policy oriented. Voters are repeatedly asked to reveal their level of approval for specific governmental institutions and for democracy in general, but not about alternatives to existing procedures and how they would like the political system to work. With the exception of a few recent advances, most surveys show a striking lack of interest in alternative, democratic political decision-making procedures. Indeed, repeated surveys have shown that there is strong support for a more frequent use of referendums (Dalton et al. 2001; Donovan \& Karp 2006; Bowler et al., 2007; Bengtsson \& Mattila 2010; Anderson \& Goodyear-Grant 2011). However, a single measurement does not provide the full story about people's preferences (Hibbing \& Theiss-Morse 2002).

There are several potential explanations for the absence of conventional survey items that are able to grasp process preferences. One important reason is that substantive changes in the way government is run have been difficult to envisage. Another reason is the underlying assumption that people lack the ability to form opinions on such complex matters as political decision-making procedures. Considering the fact that people's ability to form stable opinions on far more straightforward issues (Zaller \& Feldman 1992; Tourangeau et al. 2000), this perception is perhaps not surprising. Yet another, more practical reason is that issues at this level of complexity do not easily translate into simplistic survey questions.

Undoubtedly, it is of vast relevance for the discipline of political science to learn more about citizens' preferences for political decision making. But before embarking on the big task of providing an overview of people's true preferences on this highly complex matter, as well as accounting for these preferences, it seems appropriate to examine the extent to which it is likely to be a fruitful endeavour. The Finnish National Election Study 2011 (FNES 2011) is one of the rare exceptions to the typical non-existence of survey items dealing with political processes. The FNES 2011 includes a rich variety of questions on 
political decision making, covering both alternative procedures and several differently framed questions on the same issues. The aim of this study is to use this rich dataset in order to study the extent to which people's preferences display logical and coherent patterns in line with theoretical expectations. The issue is tackled by two different approaches: by looking at patterns among variables and among respondents.

The paper is structured as follows. The next section of the study expands upon existing research on citizens' decision-making preferences, its conclusions and shortcomings. The problems involved with measuring process preferences are discussed in the light of more general research concerning survey research and opinion stability in the following section. The empirical part of the study is then introduced by a presentation of the empirical design, including a thorough introduction to the survey items used. This is followed by the empirical analyses of preference patterns with the use of factor and cluster analysis. The study concludes with a discussion of the empirical results and its implications for future research.

\section{Process preferences. An underexploRed fieLd of ReSEARCH}

Political decision-making procedures tend to be stable, at least in advanced democracies. Most, if not all democratic systems rest on the principle of indirect representation; a system in which political parties play an important role. However, while the basic structures of democratic government in most countries have been constant over time, and support for democracy as a general principle stands high, a very different story can be told about citizens' support for the main actors and institutions of democratic government, as well as their interest in participating within the representative framework. Erosion of citizen support for parties and politicians and decreasing rates of turnout has led to growing concern among political scientists (e.g. Norris 1999; Dalton 2004), which, in turn, has caused reformists to call for new forms of political participation. It is argued that more participatory forms of democracy would help overcome some of the cynicism and feelings of disempowerment that many citizens express towards the political arena today.

Repeated surveys, complemented by a relatively rich literature, provide us with evidence of widespread popular support of one participatory mechanism; specifically, the use of referendums (Dalton et al. 2001; Donovan \& Karp 2006; Bowler et al., 2007; Bengtsson \& Mattila 2010; Anderson \& Goodyear-Grant 2011). By now, it stands clear that a majority of citizens in most advanced democracies are in favour of a more frequent use of referendums. Although it is clear that referendums are far from the only participatory mechanism that reformists are interested in, this is one of the few that are repeatedly asked in surveys.

The conclusion that a more frequent use of referendums and other forms of participatory reforms can help overcome the challenge faced by most advanced democracies has, however, been questioned. According to recent research, enthusiasm for direct democracy may reflect what people find lacking in representative democracy as much 
as it reflects interest in a more participatory version of democracy (Bowler et al. 2007; Bengtsson \& Mattila 2009). One of the main criticisms has been presented by the American scholars John Hibbing and Elisabeth Theiss-Morse. In their book Stealth Democracy (2002), they claim that people do not really want to become personally more involved in politics, and that the main reason for many respondents saying that they prefer more direct democracy in opinion surveys is that surveys generally do not offer enough relevant options for respondents to express their desire for political change (ibid., 88). The argument put forward does merit some credit since most of the research in the field is based on only single statements such as:

"Important issues should more frequently be decided by referendums" (FNES 2011)

"Referendums are a good way to decide important political questions" (ISSP 2004)

Hibbing and Theiss-Morse argue that the first preference of citizens is to make representative democracy function better, not to have more participatory forms of democracy. However, since people in general consider allowing current politicians to misuse their gained position for their own benefit to be a worse option, they reply to statements such as those above in a positive manner. In their own analyses, Hibbing and Theiss-Morse find support for what they label Stealth democracy. Stealth democracy refers to a form of a political system which instead of emphasising direct citizen involvement stresses efficiency, less debate and a more extended role for experts in the political decision making process. They reach their conclusions based on a very different set of indicators such as ${ }^{11}$ :

"Our government would run better if decisions were left up to nonelected, independent experts rather than politicians or the people."

"Elected officials would help the country more if they would stop talking and just take action on important problems."

Ironically enough, Hibbing and Theiss-Morse, who themselves have claimed that surveys in general do not offer enough alternatives for people to express their true opinions, have been strongly criticised on methodological grounds (see for example Neblo et al. 2010). The statements used in the Stealth Democracy study are indeed very colourful and do not play out different alternative forms of government against each other. Irrespectively of if their interpretation of people's preferences concerning political decision making is correct or not, an important contribution of their study is the raised awareness of the insufficient level of knowledge concerning citizens' expectations about representative democracy, as well as its alternatives.

\footnotetext{
${ }^{1}$ The two examples represent two out of four statements used in the Stealth Democracy index.
} 
The argument put forward by Hibbing and Theiss-Morse has not been warmly welcomed in the flourishing research field of participatory and deliberative democracy. One of the most ambitious attempts to question the stealth democracy thesis is the recent study by Michael N. Neblo et al. (2010). By presenting respondents with a replication of the statements used in the Stealth Democracy study, as well as a positive rewording of each of these statements (what they themselves label Sunshine democracy) alongside other measurements dealing with willingness to participate in deliberative forums of various kinds, they are able to present a more reliable and reflective view on citizens' expectations and wishes concerning participatory and deliberative procedures. And their conclusions are more in line with the popular view: people's willingness to deliberate is far more advanced than what the sceptics have put forward. The study can be considered a step in the right direction as it uses a wider selection of items such as:

"If politics were (less/more) ${ }^{2}$ influenced by self-serving officials and powerful special interests, do you think that you would be more or less interested in getting involved in politics?"

"It is important for the people and their elected representatives to have the final say in running government rather than leaving it up to unelected experts"3

Although some advances have been made in recent years, based on the current state of research about political processes it stands clear that we are lacking thorough empirical knowledge of citizen support concerning political processes. The debate regarding people's wishes is still very much open. Not very surprisingly, it appears that not all agree on how democracy should work, but rather that different visions are to be found among the general public. Exactly what these alternatives entail, how common they are and to which extent they can be considered as clearly envisaged are however, questions that remain to be answered. One of the main problems with the current state of research is not only that preferences concerning one alternative or line of development is studied at the time (stealth democracy, referendum, deliberation), but also that each study uses a different set of indicators. Yet another problem is the lack of interest concerning the currently dominating system of representative democracy. Citizens are often asked to evaluate the trustworthiness of the political system, but systematic studies of the popularity of representative democracy in comparison with other alternatives are still very much lacking. Hence, in order to get the full picture of people's preferences, it seems appropriate to offer a richer selection of process alternatives and to allow for simultaneous comparisons. If citizens are able to form opinions on these matters and hence answer

\footnotetext{
${ }^{2}$ The study asked each respondent two different versions of the question in order to control for nonseparable preferences (Lacy 2001).

${ }^{3}$ The statement is formulated opposite to one of the four statements used in the Stealth democracy index designed by Hibbing and Theiss-Morse (2002).
} 
questions of this kind in a coherent way is, however, a task that is important to investigate before embarking on these tasks.

\section{CAN WE EXPECT THAT PEOPLE KNOW WHAT THEY WANT?}

Of major concern in this study is if it is likely that citizens in general have formed opinions on such complex matters as political processes, and to what extent these opinions can be grasped by survey research. Taking into account the well-established finding that people's opinions on far more simplistic issues in general are very unstable (Converse 1964), it would at first appear as rather unlikely. If people in general have difficulties forming stable opinions on far more simplistic issues and the answers retrieved from surveys are very sensitive to the order in which questions are posed or the wording used ${ }^{4}$; how should they be able to answer questions concerning political decision-making procedures in a logical and coherent manner?

The current state of research tells us that the instability in attitudes expressed in surveys is due to many different reasons. Firstly, there is always the risk that instability and inconsistency stems from lack of interest, comprehension, knowledge or consideration on behalf of the respondents. These aspects are likely to result in nonsubstantial responses such as missing cases or don't knows but also in unexplained "noise", always present in survey research. When confronted with survey items that deal with complex issues that are not actively considered on a daily basis, such as political decision-making procedures, it is likely that the share of non-response or pure random response will increase.

But attitude volatility is not necessarily only due to lack of engagement or comprehension. In the literature on public opinion, the unstable attitudes of many citizens are often described as ambivalence (Lavin 2001; Steenbergen \& Brewer 2000; Craig et al. 2005). It is now widely acknowledged that political opinions are not simply positive or negative but often both simultaneously. Citizens, who to some extent agree with two different sides of a political conflict, should not necessarily be accused of not having an opinion (Converse 1964). Moreover, it does not automatically reflect insufficiencies in survey instruments (Achen 1975). Rather, these more commonly complex attitudes often represent a problem of reconciling strongly held, but conflicting principles and consideration (Alvarez \& Brehm 1995; Zaller \& Feldman 1992). Ambivalence is hence a prevalent characteristic of the public's political opinions, and it does have an impact on political judgement and choice. The extent to which people display stable and coherent attitudes in surveys may consequently depend on how consistent their internal views about an issue are, or how

\footnotetext{
${ }^{4}$ Two problems that have been described as major types of "artifactual" variance in survey research (Zaller \& Feldman 1992).
} 
homogenous the considerations that are recalled when confronted with a survey question are. ${ }^{5}$ People with relatively homogeneous or one-sided views will come up with consistent answers even if they do not retrieve the same considerations. By contrast, those with mixed underlying views are likely to give different responses when their answers are based on different considerations.

It is not easy to determine what level of ambivalence is likely to be apparent when dealing with attitudes towards political processes. At first, it might seem likely that these types of systemic and complex issues are more likely than others to involve ambivalent considerations. A rich variety of arguments pro and con certain decision-making procedures are easy to come up with and it is indeed not easy to pinpoint the perfect political system. On the other hand, one might very well argue the opposite. Ambivalence implies familiarity with various pro and con arguments on a specific issue, which is less likely to exist for issues of lower salience, where attitudes are less thoroughly considered in the first place.

Yet another important aspect to take into account when trying to measure opinions of any kind is the fact that survey questions do not simply measure public opinion, they also form it by the way in which questions are framed. It might even be that no true attitudes exist, but rather a balance of considerations where the result attained is dependent on the way the survey items are contextualised. The formulation of questions, the alternatives respondents are offered to take a stand on, and the order in which they are presented all have implications for the way respondents answer questions (Zaller \& Feldman 1992; Tourangeau 2000). Thinking about format and framing from the perspective of this study, it is very likely that these types of effects will be stronger when dealing with matters with a high level of complexity or issues of low salience. But they are also likely to be emphasised when ambivalence is high due to their impact on the specific considerations that come into mind.

Based on experience from the field of social and political psychology, it stands clear that attempts to measure peoples' preferences of all kinds should be done with care, but also that preferences for political decision making are likely to be more sensitive to many of these types of instability effects than other issues. Due to the complex nature of the matter of interest and the sensitivity to the way questions are posed, the outcome of specific survey items should not be considered a snapshot of the public's true opinions. However, if it is possible to find coherent patterns or trends in the way in which people

\footnotetext{
${ }^{5}$ According to the belief-sampling model (Tourangeau et al. 2000), instability is natural since the attitudes expressed in surveys are formed based on a sample of considerations, which happen to be activated at that specific moment. These considerations are in turn taken from the extensive database in our brain consisting of many previous evaluations, vague impressions, general values and relevant feelings and beliefs (Zaller 1992). As a result, the considerations that happen to be activated when the respondent is confronted with a certain question will be over-represented in the answer given. Which considerations are accessible is, in turn, influenced by a large number of factors such as the strength of the considerations, the context of the question or what considerations have recently been activated.
} 
answer these questions, this finding should be considered important. Knowing that voters have preferences concerning political processes, even if they turn out to be vague, and that there is a cross-sectional variation in these preferences is a sufficient point of departure for future citizen-based studies on this topic.

\section{EMPIRICAL DESIGN}

The empirical analyses of the study are performed using cross-sectional survey data from the Finnish National Election Study (FNES) 2011 (FSD2653). ${ }^{6}$ The FNES2011 is a national representative post-election study performed after the Parliamentary election in April 2011. The study involves face-to-face interviews with a total of 1,298 respondents based on quota sampling ${ }^{7}$ and a self-administered questionnaire, returned by mail by 806 respondents. ${ }^{8}$ Due to the fortunate influence of scholars with a specific interest in process preferences, the FNES 2011, contrary to most other national election studies, includes a rich variety of survey items designed to grasp process attitudes and hence constitutes a very suitable source of data for these types of analyses. Since a vast majority of the items of interest were included in the selfadministrated questionnaire, only respondents that have taken part in both parts of the survey are included in the analyses $(\mathrm{N}=806)$. Three different types of survey items covering attitudes towards political decision making (presented below) will be analysed in the empirical section.

In order to determine if there are logical patterns in peoples' preferences towards these issues and if these patterns are in line with what is suggested in previous research, a combination of different empirical analyses will be utilised. The first empirical analysis will involve looking for patterns in the way people respond to the different measurements with the use of factor analysis. While factor analysis provides information about the degree to which variables correlate, it does not tell us much about similarities among individuals. The second empirical section will therefore use cluster analysis in order to find groups of individuals who share the same belief system structure (Fleishman 1986), and also to map the opinions held by individuals in each of the clusters to show they differ from each other.

\footnotetext{
${ }^{6}$ Data are available at the Finnish Social Science Data Archive: www.fsd.uta.fi.

${ }^{7}$ The quotas were based on age, gender, and province of residence of the respondents.

${ }^{8}$ The face-to-face interviews were conducted within five weeks of the election (18 April-28 May 2011). The last self-administered questionnaire was returned by the 14th of June 2012.
} 


\section{Grasping preferences for political decision making}

Even though not of primary interest for the purpose of this study, a highly interesting question is of course what type of political decision making Finnish citizens prefer. In line with the literature review above, the nine questions included in this study are designed to grasp attitudes towards political processes of three different types or models: 1) more citizen involvement in political decision making; 2) pure representative practices; and 3) a more pronounced role for un-politicised, independent experts.

Three different types of survey items will be presented and analysed: 1) statements using a four point disagree/agree scale; 2) overarching, unidimensional questions using an eleven-point worst/best scale; and 3) two-dimensional questions about two different ways of making political decisions using an eleven-point continuum. The different questions are presented in more detail below and in Table 1.

The first type of questions are presented as single and relatively detailed statements about political decision-making processes, often related to how the political arena is functioning today. In this section three statements are included: one about referendums, one about political discussions for ordinary people, and one about experts making political decisions. The last statement is replicated from the Stealth Democracy study by Hibbing and Theiss-Morse (2002) where respondents are requested to specify their general level of agreement or disagreement with the statements on a four-point scale. ${ }^{9}$

Respondents are asked about their opinions towards the first two statements early on in the face-to-face part of the study and they are presented in conjunction with nine other statements on aspects related to voting. The statement about the role of experts is asked in the first third of the questionnaire together with 13 other statements, many of which are replications from the Stealth Democracy study but which are not relevant for the purpose of this study. They are relatively provocatively phrased and clearly designed to activate considerations dealing with efficiency.

Looking at the response pattern for the different statements it becomes apparent that they vary a great deal. In particular, the respondents' reactions towards the statement "Finland would run better if political decision making were left to independent experts rather than politicians or the people" are negative. The statement can indeed be described as colourful and provocative, which is likely to contribute to the distribution of answers. However, considering the well-established acquiescence response bias for statements using agree/disagree response alternatives (Saris et al. 2010), this clearly negative distribution can be considered somewhat surprising. The distribution for the

\footnotetext{
${ }^{9}$ It should be noted that the formulation of the statement deviates slightly from the one used by Hibbing and Theiss-Morse due to the translation. The content of the statement does, however, correspond with the original. "Don't know" was offered in the self-administrated questionnaire. The statement about referendums and political discussions asked in the face-to-face part of the study only reported spontaneous "don't know" answers.
} 
Table 1.

Survey items about political decision-making procedures included in the study

Statements $\quad$ No intro used. Response categories: Strongly disagree, disagree, agree, strongly agree

1

Important national issues should more frequently be decided in referendums (f2f)

2.

Political discussions for ordinary people should be arranged in support of representative democracy (f2f)

3. Finland would run better if political decision-making were left to independent experts rather than politicians or the people $(Q)$
Mean: 0.61, SD: 0.34, N: 795,

Don't know: 11

Mean: 0.64, SD: $0.29, \mathrm{~N}: 774$,

Don't know: 32

Mean: 0.32, SD: 0.29, N: 719 , Don't know: 77, Missing: 10

\section{Unidimensional questions}

Intro: What is your opinion on the following forms of political decision making? Provide your opinion on a scale from 0 to 10 , where 0 means 'the worst way of making political-decisions' and 10 'the best way of making political decisions'. (Q)
1. Regularly ask citizens about their opinions

2. Let experts in different areas make decisions

3. Make it easier for people to participate and discuss important political decisions

4. Let elected politicians make decisions
Mean: 0.70, SD: 0.22, N: 793, Missing: 13

Mean: 0.57, SD: 0.24, N: 789, Missing: 17

Mean: 0.72, SD: 0.18, N: 792, Missing: 14

Mean: 0.63, SD: 0.23, N: 794 , Missing: 12

Two-dimensional questions

Intro: There are different opinions about political decision making. Please give your opinion about the following statements on a scale of 0 to 10 by marking the number that best corresponds to your view. $(\mathrm{Q})$

0

10

a.

Ordinary people should make Popularly elected representatives Mean: 0.68, SD: 0.24, N: 775, political decisions should make political decisions Missing: 31

b. Politically independent experts Popularly elected representatives Mean: 0.71, SD: $0.23, \mathrm{~N}: 777$, should make political decisions Missing: 29

Note: $Q=$ item included in the If-administrated questionnaire, f2f= item included in the face-to-face interview. All items are recoded on a scale of 0 to 1 . 
two other statements about referendums and political discussions both lean towards the agreeing-side of the scale although with a different strength, but with slightly higher support for political discussions than referendums. Yet another interesting observation is that the share of non-substantial answers is substantially higher for the last, and rather provocatively phrased statement about independent experts, but also higher for the statement concerning political discussion. This is probably due to the fact that these two statements deal with issues that are likely to be new to many people. ${ }^{10}$

In the second set of questions, respondents are confronted with four different political decision-making alternatives and are asked to rank the four alternatives one at a time on a scale from 0 ('the worst way of making political decisions') to 10 ('the best way of making political decisions'). ${ }^{11}$ Two of the alternatives are in favour of more citizen involvement in politics, one is in favour of political decisions made by elected representatives, and another in favour of political decisions made by field experts. The items appear at the beginning of the questionnaire after several policy questions. Despite the obvious contradictions involved in some of the alternatives offered, and the fact that respondents have answered the questions in a successive manner ${ }^{12}$, it is obvious that respondents tend to be very positive about all of them. There are slight differences concerning the degree, but all are evaluated well above the mean. The results are not very promising in these cases, neither concerning the stability of attitudes held by respondents nor concerning the construct of the survey item. The most positive attitudes are found for the two alternatives that involve more citizen involvement, while the least positive attitudes are found for experts as decision makers.

The third and last group of questions are two-dimensional. Here respondents are confronted with two different political decision-making alternatives simultaneously. The two alternatives are presented at each end of an eleven-point continuum, and respondents are asked to present their view on the scale. The design of the questions obliges respondents to make a choice rather than being able to agree with alternatives that can be considered contradictory. The two different pairs of alternatives offered to respondents are: politically independent experts or popularly elected representatives, and ordinary citizens or popularly elected representatives. ${ }^{13}$ These questions are asked towards the end of the questionnaire ${ }^{14}$ and they are designed to make respondents aware of the

\footnotetext{
${ }^{10}$ The "don't know" response alternative was not offered for any other item used in the study, except for the statement on independent experts replicated from the Stealth Democracy study.

11 "Don't know" was not offered as an alternative. The four questions are replicated from a Spanish survey (January 2011) conducted by the Centro de Investigaciones Sociológicas (CIS).

12 The four different questions were presented as one overarching question concerning "the best or worst way to make political decisions", including four different sub-questions.

${ }^{13}$ Unfortunately, the questionnaire did not include a question asking respondents to choose between ordinary citizens and independent experts.

${ }^{14}$ One question was asked before the two questions mentioned above using the same scale and format. This question asked about the importance of discussions and debates compared to effective decision making and is not included in the analyses.
} 
internal contradiction between the two options offered and hence to activate considerations that take into account both alternatives. They are likely to stimulate respondents to choose which alternative they see as the most attractive one or the option that is more in line with their underlying preference. By forcing respondents to choose between two alternatives, these questions also presuppose an antagonistic model where different alternatives are seen as mutually exclusive rather than complementary. Looking at the distribution of answers to these questions, it is clear that there is a tendency towards high values, a tendency that corresponds to the one found for "the best way" questions discussed above. Here, it does however appear as likely that the distribution is driven by the actual contents of the questions rather than the format since high values in both cases indicate support for decision-making processes dominated by elected representatives. ${ }^{15}$ The share of non-responses is higher for these two questions than for the "best way" items, but considering that respondents were forced to make a choice and the fact that these items were placed at the end of a rather long questionnaire, the share should not be considered alarming.

A general remark regarding the distribution of answers to the nine different survey items about the different decision-making procedures presented above is that people appear to express non-consistent attitudes. Clearly, the positive judgements made in the "best way" items are contradictory. Moreover, while the two last questions demonstrate very strong support for political processes where elected representatives take care of decision making (rather than experts or ordinary people), a more frequent use of referendums or political discussions for ordinary people get strong support in the first two statements. By merely looking at the distribution of answers it is hence impossible to make a positive evaluation about the consistency in which people answer survey questions on political decision-making procedures or regarding the fruitfulness of analysing these answers more closely. Rather, the distributions clearly indicate that all types of decision making are highly rated, a result that looks like a response bias along the same line.

\footnotetext{
${ }^{15}$ In order to separate the effects of format and content, it would have been more effective to turn the scale around for one of the alternatives. However, when looking at the distribution for a third question with the same format included in connection with the two items used here, it seems as if the format effect is not overwhelming. This third item used the same intro about different opinions (see Table 1) where zero was presented as "In politics it is important to discuss a debate thoroughly before making decisions" and ten "In politics it is important to make decisions rather than to discuss and debate". Here the distribution did lean towards the left-hand side (that is closer to zero) with a mean of 0.48 .
} 


\section{EMPIRICAL ANALYSES}

In order to answer the overarching research questions set out in this study -if there are logical patterns in peoples' preference towards political decision making, and if so, if these patterns correspond to what is set out in previous research in the field - a combination of empirical analyses will be performed. The first step involves factor analysis, and is able to tell us the degree to which the nine variables of interest correlate and constitute different dimensions. This strategy does not, however, tell us much about similarities among individuals. In order to study the extent to which there are groups of individuals who share the same belief system structure (Fleishman 1986) cluster analysis will be applied in the second step of the empirical analysis.

\section{Preference patterns}

The first analysis, involving a search for dimensions in the attitudes expressed by respondents, provides us with a result that is far more encouraging than by merely looking at the distribution of answers. In fact, the principal component analysis using Varimax rotation and extracting components with Eigenvalues above 1, which is presented in Table 2, results in three different dimensions that very much correspond to expectations based on previous research.

The first dimension is constituted by preferences in line with representative decisionmaking procedures. Four items load relatively strongly onto this dimension; three items that explicitly mention elected representatives as decision-makers, and one indirect measure of the use of referendums. The second dimension can be described as an enhanced role for citizens in decision making. Four different items, all in favour of a more extended role for citizens load onto this dimension. The third and last dimension is constituted of preferences in favour of using experts in decision making. All of the three different items that explicitly deal with the role of experts load onto this dimension. Overall, the pattern appears to be logical and support the existence of attitudes that have been put forward in the literature. According to these results, the way in which respondents confronted with survey items concerning political processes respond indicate at least some level of consistency. Moreover, the answers are structured along the different lines that have been pointed out in previous research.

The second dimension, labelled "direct citizen involvement", does however merit a more thorough discussion. In the introduction to this study, the three different alternatives were presented as more or less antagonistic models of decision-making procedures. Either we assign power to citizens, elected representatives, or to experts. According to the factor analysis presented in Table 2, this is not necessarily how it is perceived by citizens themselves. The peculiarity is found in the two-dimensional item where respondents are asked if ordinary people or elected representatives should make decisions. 
Table 2.

Principal component analysis of the eight items

(Varimax rotation, rotated component matrix)

\begin{tabular}{lccc}
\hline & \multicolumn{3}{c}{ Components } \\
& $\begin{array}{c}\text { Representative } \\
\text { democracy }\end{array}$ & $\begin{array}{c}\text { Direct citizen } \\
\text { involvement }\end{array}$ & Experts \\
\hline DO: Ordinary people/Elected representatives & $\mathbf{0 . 7 4}$ & 0.02 & -0.16 \\
BW: Elected politicians & 0.71 & -0.09 & 0.08 \\
S: Referendums & -0.59 & 0.43 & -0.17 \\
DO: Independent experts/Elected represen- & 0.56 & 0.14 & -0.54 \\
tatives & & & \\
BW: Participate and discuss & 0.14 & 0.81 & 0.05 \\
BW: Ask citizens & -0.25 & 0.77 & 0.04 \\
S: Political discussions & -0.04 & 0.50 & -0.22 \\
BW: Experts & 0.28 & -0.00 & $\mathbf{0 . 8 0}$ \\
S: Experts & -0.21 & -0.08 & 0.74 \\
\hline Eigenvalues & 2.13 & 1.87 & 1.21 \\
\% of variance & 23.6 & 20.8 & 13.5 \\
\hline
\end{tabular}

Note: S: Statement, BW: Best way, DO: Different opinions. Extraction Method: Principal Component Analysis.

Rotation Method: Varimax with Kaiser Normalization.

This item does not load negatively onto the dimension of citizen involvement ${ }^{16}$ even though it seems as if an attitude pointing in the direction towards a stronger role for citizens in decision making (rather than elected representatives) would go hand in hand with more direct citizen involvement. A likely explanation is that the dimension explicitly captures positive attitudes towards more citizen involvement, but without implying attitudes in favour of a democratic system where citizens would be responsible for making all political decisions. It is hence support for a model where the role of citizens is extended, and functions as a complement to pure representative structures, for example in the process of will-formation, rather than as an antagonistic model where citizens replace elected representatives as decision makers.

${ }^{16}$ The loading is expected to be negative since a positive loading would indicate that respondents in favour of more citizen involvement in politics would prefer elected politicians to make decisions. As it turns out, the loading is close to zero. The way respondents answer this question is not connected to their responses to the items that load strongly onto this dimension. 


\section{Similar belief structures}

The previous section showed that it is indeed possible to detect response patterns in line with the theoretical expectations outlined above although with minor exceptions. So far we can thus conclude that the way in which respondents answer questions concerning political decision-making procedures is not purely random. The factor analysis does, however, tell us little about similarities or differences among groups of individuals. This last empirical section turns the question around and examines the extent to which it is possible to identify groups of individuals who have answered the nine different items in a similar manner and if so, how many these groups are and how they have responded. Hence, instead of studying patterns among variables this second analysis is focused on patterns among individuals (Fleishman 1987).

This is done by applying a two-step cluster analysis using Schwarz's Bayesian criterion (BIC), a method designed to automatically reveal natural groupings within a dataset that would otherwise be hard to detect. ${ }^{17}$ The analysis results in three different clusters, that is, the same amount as the number of components detected in the factor analysis presented above. The fit is, however, specified as fairly poor, which indicates that cohesion among, and separation between, the clusters is relatively low. But given that we are dealing with complex matters, a low degree of cohesion is hardly surprising. In order to get a picture of the groups detected by the cluser analysis, the mean values of each of the variables are presented in Table 3 along with Eta ${ }^{2}$-values that should be interpreted as the percentage of variance accounted for by each variable (Levine \& Hullett 2002). In order to make the interpretation of the table more straightforward, the highest group means are marked in bold and the second highest in italics.

The cluster that stands out as the most distinct and easiest to interpret is cluster number 3, labelled "representative democracy". The 170 respondents that constitute this cluster stand out as strong supporters of a representative political system. On average they display the most positive opinions towards placing, or rather preserving, decision-making power in the hands of elected representatives. The result is found for all of the three items that explicitly offers this as an option. At first glance it may seem somewhat surprising that this group also displays the most positive view towards arranging political discussions for ordinary people. However, when taking into account the complete wording of this item, the picture becomes clearer; the addition in the end of the statement "... in support of representative democracy" clearly provides a positive signal in favour of placing decision making in the hands of popularly elected

\footnotetext{
${ }^{17}$ The Bayesian information criterion $(\mathrm{BIC})$ is a criterion for model selection among a finite set of models. It is based, in part, on the likelihood function.
} 
Table 3.

Opinions towards political decision making by clusters (means)

\begin{tabular}{lcccc}
\hline & \multicolumn{4}{c}{ Clusters } \\
\hline & 1 & 2 & 3 \\
\cline { 2 - 5 } & $\begin{array}{c}\text { Technocratic } \\
\text { government }\end{array}$ & $\begin{array}{c}\text { Direct citizen } \\
\text { involvement }\end{array}$ & $\begin{array}{c}\text { Representative } \\
\text { democracy }\end{array}$ & Eta $^{2}$ \\
\hline DO: Ordinary people/Elected representatives & 0.76 & 0.59 & 0.84 & 0.21 \\
BW: Elected politicians & 0.68 & 0.51 & 0.76 & 0.21 \\
S: Referendums & 0.41 & 0.83 & 0.55 & 0.29 \\
DO: Independent experts/Elected representatives & 0.67 & 0.56 & 0.86 & 0.22 \\
BW: Participate and discuss & 0.67 & 0.77 & 0.74 & 0.06 \\
BW: Ask citizens & 0.59 & 0.81 & 0.68 & 0.19 \\
S: Political discussions & 0.51 & 0.68 & 0.74 & 0.10 \\
BW: Experts & 0.62 & 0.53 & 0.52 & 0.04 \\
S: Experts & 0.34 & 0.40 & 0.16 & 0.12 \\
\hline (n) & $(231)$ & $(256)$ & $(170)$ & $(657)$ \\
\hline
\end{tabular}

Note: All differences between groups are significant $p<0.001$ (ANOVA). Clusters are retrieved from a two-step cluster analysis with Schwarz's Bayesian criterion (BIC). S: Statement, BW: Best way, DO: Different opinions.

representatives. ${ }^{18}$ Respondents in this third cluster can also be characterised as having a negative attitude towards experts in decision making.

The second cluster comprises 256 respondents which can largely be characterised as having a positive view of more direct citizen involvement. Moreover, they express less enthusiastic views towards elected representatives than the other two groups. This becomes apparent in both of the two-dimensional items where the respondents in this cluster are less inclined to provide an answer towards the end of the "elected representatives" scale, regardless of whether it is ordinary people or independent experts that constitute the point of comparison. Along the same line this group of respondents is inclined to agree with the statement that "Finland would run better if political decision making were left to independent experts rather than politicians or the people". Taken as a whole, the respondents in this cluster are in favour of people having a larger say in politics, but it also appears that other

\footnotetext{
${ }^{18}$ Moreover, in the Finnish translation, the part mentioning "representative democracy" appears in the introduction to the statement.
} 
alternatives, such as expert rule, are considered, as long as political power moves away from elected representatives. This result is in line with a previous study among Finnish citizens showing that many people want change to the existing situation but they do not necessarily have well-thought-out options for the direction this change should take (Bengtsson \& Mattila 2009).

Cluster number one, consisting of 231 respondents and labelled "technocratic government", is most easily characterised by what they do not want, rather than what they want. This group is shares a sceptical attitude towards greater citizen involvement, or rather, they are more dubious than the respondents in the other two clusters. This group displays the lowest mean for all of the items that are designed to grasp perceptions of a more extended role for citizens in political life, that is, a more frequent use of referendums to make it easier for citizens to participate and discuss, frequently ask citizens and to arrange political discussions for ordinary people. The type of political decision making that this group of respondents favours is far less clear cut. It appears as if a mixture of experts and elected politicians is the answer. This group shows the most positive attitudes towards experts as decision makers, but the level of approval of elected representatives is generally high.

When looking at which survey items are able to differentiate the three groups from each other, it is clear that the statement about referendums displays the highest explanatory power eta ${ }^{2}=0.29$ ), followed by the two questions asking respondents to choose between different decision makers (independent experts/elected representatives and ordinary people/elected representatives) as well as the "best way" item asking about elected politicians. This, in turn, can be interpreted as favourable for the survey items as such since it appears that respondents are able to single out different preferences that exist among the public. Symptomatic of these items are that they either deal with aspects that are familiar to people, such as referendums or elected politicians, or that they offer respondents a clear choice between two alternatives. The survey items that have the lowest explanatory power all cover features that occur less frequently in public discussions, and hence are less likely to be familiar to general citizens. This is particularly true for the role of experts as decision makers or the use of deliberative tools such as political discussions.

Taken as a whole, the cluster analysis demonstrates that it is possible to identify groups of citizens that have different opinions towards political decision making. The interpretation of the contents of these clusters is, however, slightly different than the patterns found in the factor analysis. In both analyses a positive view of representative structures and a greater role for citizens in political decision making is a common denominator. However, we cannot identify a group of people that can be characterised as being strongly in favour of the role of experts in decision making, rather we get a group that is very sceptical towards an enhanced role for the people. Not very surprisingly we also find that survey items that cover more familiar decision-making procedures work better when it comes to differentiating between groups of citizens with diverse views on the subject than items with less common aspects. 


\section{CONCLUDING DISCUSSION}

Empirical research on citizens' preferences concerning political decision making has expanded during recent years. Despite this growing interest, several basic questions still remain open. The aim of this study has been to contribute to a relatively new field of research by exploring to what extent attitudes expressed by citizens display coherent and logical patterns in line with the expectations reported in previous research.

For those interested in understanding how people think about political decisionmaking procedures, this study has provided a few positive results. First of all, it seems clear that we can find other types of preferences for political decision making than "more power to the people". Hibbing and Theiss-Morse (2002) are hence on the right track when they claim that surveys that only measure opinions towards more participatory forms of democracy do not provide the full picture. In order to gain knowledge concerning peoples' expectations regarding political decision making and how these expectations vary among the general public, it is important to incorporate a more diverse set of questions on these topics into the standard repertoire of surveys. Moreover, when looking at patterns found among different survey items, it appears as if people, at least to some extent, are able to express their opinions towards political processes and that the answers they provide are along the same lines as outlined in the theoretical literature.

It does, however, also stand clear that survey items that cover political decisionmaking procedures that are more familiar to the general public function better when it comes to distinguishing between different opinions. When asking about less well-known aspects of political processes it seems to be good advice to go beyond the model with simple (and provocatively phrased) statements and instead provide respondents with more and balanced information concerning the procedures that are of interest. The more complex the issues get, the greater the risk of affecting the outcome by the way questions are contextualised, formulated and formatted.

The interpretation of attitudes held by respondents does, however, vary depending on the point of departure, the correlation among variables or the correlation among respondents. When departing from variables in the correlation and factor analysis, it stands clear that the patterns detected are in line with theoretical expectations; answers to items about the role of experts in decision making, representative procedures and an extended role of citizens are connected. The result can be interpreted in two ways. Firstly, it corroborates expectations about the contents and direction of attitudes presented in previous literature in the field. Secondly, it is a confirmation of consistency in the way that people answer survey questions on the topic.

When we search for patterns among respondents rather than variables, it stands clear that cohesion is far from perfect, but that the groups that are formed make sense and provide new insights about the composition of people's belief structures. One of the most intriguing findings is that the role of citizens in decision making appears to constitute a dividing element; while some are strongly in favour of enhanced citizen involvement, others prefers anything but that. 
To conclude, it stands clear that the opinions expressed by respondents in the Finnish National Election Study 2011 were not random. Rather we find fairly distinct and logical patterns. Future attempts to grasp people's preferences towards different decisionmaking procedures should therefore not be considered as vain endeavours. However, when measuring peoples' preferences for political processes, it is necessary to proceed with caution. Measuring peoples' opinions towards political processes should hence be done carefully and answers to single items should not be taken as a stable attitude.

\section{REFERENCES}

Achen, C. 1975. "Mass Political Attitudes and the Survey Response." American Political Science Review. 69:1218-31.

Alvarez, R. Michael and J. Brehm 1995. "American Ambivalence Towards Abortion Policy: Development of a Heteroskedastic Probit Model of Competing Values." American Journal of Political Science 39: 1055-1082.

Anderson, C. and E. Goodyear-Grant. 2010. "Why are highly informed citizens sceptical of referenda?" Electoral Studies 29:227-238.

Bengtsson, Å. and M. Mattila. 2009. "Direct Democracy and its Critics: Support for Direct Democracy and (Stealth) Democracy in Finland." West European Politics 32(5):1031-1048.

Bowler, S., Todd D. and J. A. Karp. 2007. "Enraged or Engaged? Preferences for Direct Citizen Participation in Affluent Democracies." Political Research Quarterly 60(3):351-362.

Converse, P. E. 1964. "The Nature of Belief Systems in Mass Publics." Pp. 206-261 In Ideology and Discontent edited by Apter, David. New York: Free Press.

Craig, S. C., Martinez, M. D. Kane J. G. and J. Gainous. 2005. "Core Values, Value Conflict, and Citizens' Ambivalence about Gay Rights." Political Research Quarterly 58(1):5-17.

Dalton, R. J. 2004. Democratic Challenges, Democratic Choices. The Erosion of Political Support in Advanced Democracies. Oxford: Oxford University Press.

Dalton, R. J., Bürklin W. and A. Drummond. 2001. "Public Opinion and Direct Democracy." Journal of Democracy 12(4):141-153.

Donovan, T. and J. A. Karp. 2006. "Popular Support for Direct Democracy." Party Politics 12(5): 671-688.

Fleishman, J. A. 1986. "Types of Political Attitude Structure: Results of a Cluster Analysis." The Public Opinion Quarterly 50(3):371-386.

Hibbing, J. R. and E. Theiss-Morse. 2002. Stealth Democracy. Americans' Beliefs about How Government Should Work. Cambridge: Cambridge University Press.

Hochschild, J. 1981. What's Fair? American Attitudes toward Distributive Justice. Cambridge: Harvard University Press.

Lacy, D. 2001. "A Theory of Nonseparable Preferences in Survey Responses." American Journal of Political Science 45(2): 239-258. 
Lavin, H. 2001. "The Electoral Consequences of Ambivalence toward Presidential Candidates." American Journal of Political Science 45(4):915-929.

Levin, T. R and C. R. Hullett. 2002. "Eta Squared, Partial Eta Squared, and Misreporting of Effect Size in Communication Research." Human Communication Research 28(4):612-625.

Neblo, M. A., Esterling, K. M., Kennedy, R. P., Lazer, David M.J. and A. E. Sokhey. 2010. "Who Wants To Deliberate - And Why?." American Political Science Review 104(3):566-583.

Norris, P., eds. 1999. Critical Citizens. Global Support for Democratic Governance. Oxford: Oxford University Press.

Saris, W. E., Revilla, M., Krosnick J. A. and E. M. Shaeffer. 2010. "Comparing Questions with Agree/ Disagree Response Options to Questions with Item-Specific Response Options." Survey Research Methods 4(1): 61-79.

Steenberger, M. R. and P. R. Brewer. 2000. "The Not-So-Ambivalent Public. Policy Attitudes in the Political Culture of Ambivalence." Pp. 93-129 in The Issue of Belief: Essays in the Intersection of Non-Attitudes and Attitude Change edited by Willhem E. Saris and P. M. Sniderman. Cambridge: University Press.

Tourangeau, R., Rips, L. J. and K. Rasinski. 2000. The Psychology of Survey Response. Cambridge: Cambridge University Press.

Zaller, J. R. 1992. The Nature and Origins of Mass Opinion. Cambridge: Cambridge University Press.

Zaller, J. R. and S. Feldman. 1992. "A Simple Theory of the Survey Response: Answering Questions versus Revealing Preferences." American Journal of Political Science. 36(3):579-616.

Åsa Bengtsson is an Academy Research Fellow and Docent of Political Science at Åbo Akademi University, Finland. She has published on public opinion, voting behaviour, political participation, and minority politics. Currently she is directing a research project on citizens' preferences for political decision making, financed by the Academy of Finland. 